\title{
The dose to Irish seafood consumers from Technetium-99
}

\author{
V. Smith, M. Fegan, J. Wong and S. Long \\ Radiological Protection Institute of Ireland, 3 Clonskeagh Square, Clonskeagh Road, \\ Dublin 14, Ireland
}

\begin{abstract}
In this study, the effects of ${ }^{99} \mathrm{Tc}$ discharges from Sellafield to the Irish Sea on activity concentrations in fish and shellfish landed at ports on the north-east coast of Ireland and the resultant committed effective doses to typical and heavy consumers of seafood since 1990 are presented. Technetium99 activity concentrations in fish and shellfish from the Irish Sea increased in the mid-1990s in line with increased discharges from Sellafield. In $2003,{ }^{99} \mathrm{Tc}$ discharges were reduced and have now returned to the levels of the early 1990s. Although there has been a reduction in ${ }^{99} \mathrm{Tc}$ activity concentrations in fish and shellfish landed at ports on the north-east coast of Ireland, the dose to Irish seafood consumers has not returned to the baseline levels of the early $1990 \mathrm{~s}$, being greater by a factor of two. In $2006,{ }^{99} \mathrm{Tc}$ accounted for approximately $15 \%$ of the total dose $(0.16$ and $0.75 \mu \mathrm{Sv}$ for typical and heavy consumers, respectively) to Irish seafood consumers from all artificial sources of radioactivity in the Irish Sea.
\end{abstract}

\section{INTRODUCTION}

In 1994, the discharges of ${ }^{99} \mathrm{Tc}$ from the reprocessing plant at Sellafield, in the north-west of England, to the Irish Sea increased significantly due to the processing of a backlog of liquid waste through the Enhanced Actinide Removal Plant (EARP) at the site (Fig. 1). The mean annual discharge of ${ }^{99} \mathrm{Tc}$ for the period 1994-1997 was approximately 30 times that for the period 1990-1993, with the peak in discharges occurring in 1995.

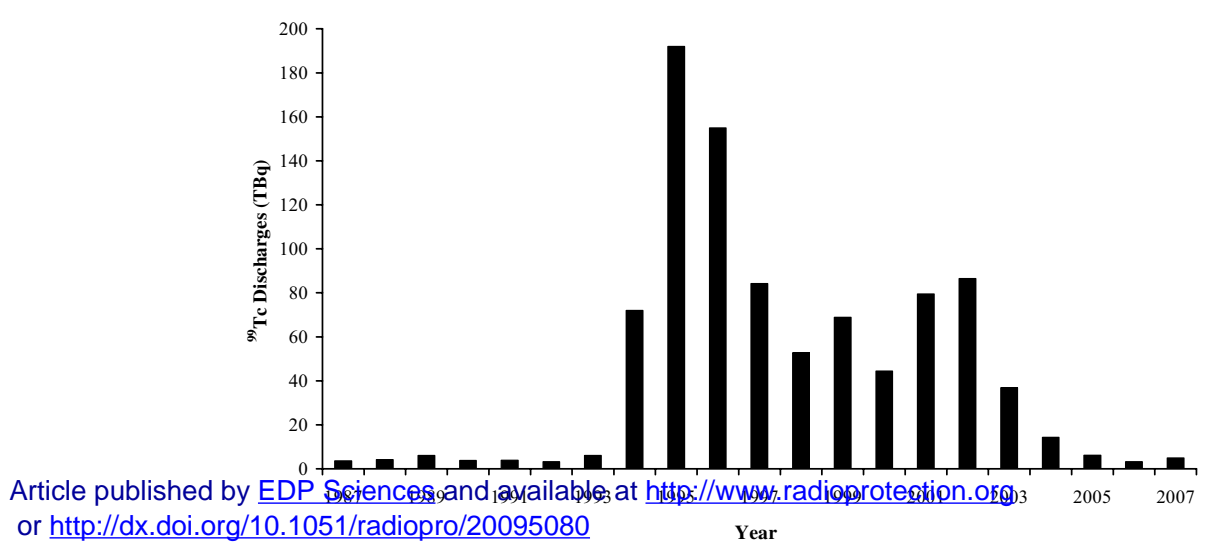

Figure 1. Marine discharges of ${ }^{99} \mathrm{Tc}$ from Sellafield, 1987-2007.

The ${ }^{99} \mathrm{Tc}$ discharges from Sellafield were reduced in 2003 when newly created Medium Active Concentrate (MAC) waste was re-routed to the vitrification plant instead of being treated in EARP. Further reductions were achieved in 2004 when a new process using tetraphenylphosphonium bromide (TPP) was introduced in EARP to remove ${ }^{99} \mathrm{Tc}$ from existing MAC being treated at the plant. 
In this study, the effects of these discharges on the ${ }^{99} \mathrm{Tc}$ activity concentrations in fish and shellfish and the resultant committed effective doses to consumers of seafood landed at ports on the north-east coast of Ireland since 1990 are presented.

\section{MATERIALS AND METHODS}

Since 1996, ${ }^{99} \mathrm{Tc}$ activity concentrations have been routinely measured in fish and shellfish landed at major fishing ports, including Clogherhead and Carlingford on the north-east coast of Ireland (Fig. 2), by the Radiological Protection Institute of Ireland (RPII). In addition, a number of fish and shellfish samples from the period 1990 to 1994 were analysed in order to establish pre-EARP baselines for the species studied. Technetium-99 activity concentrations in fish and shellfish were determined according to the method of Harvey et al. [1]. In this procedure, rhenium is used as a yield tracer and following chemical separation and purification ${ }^{99} \mathrm{Tc}$ and rhenium are precipitated as tetraphenyl arsonium pertechnetate and perrhenate, respectively. Activity concentrations and $1 \sigma$ uncertainties are expressed in $\mathrm{Bq} / \mathrm{kg}$, fresh weight.

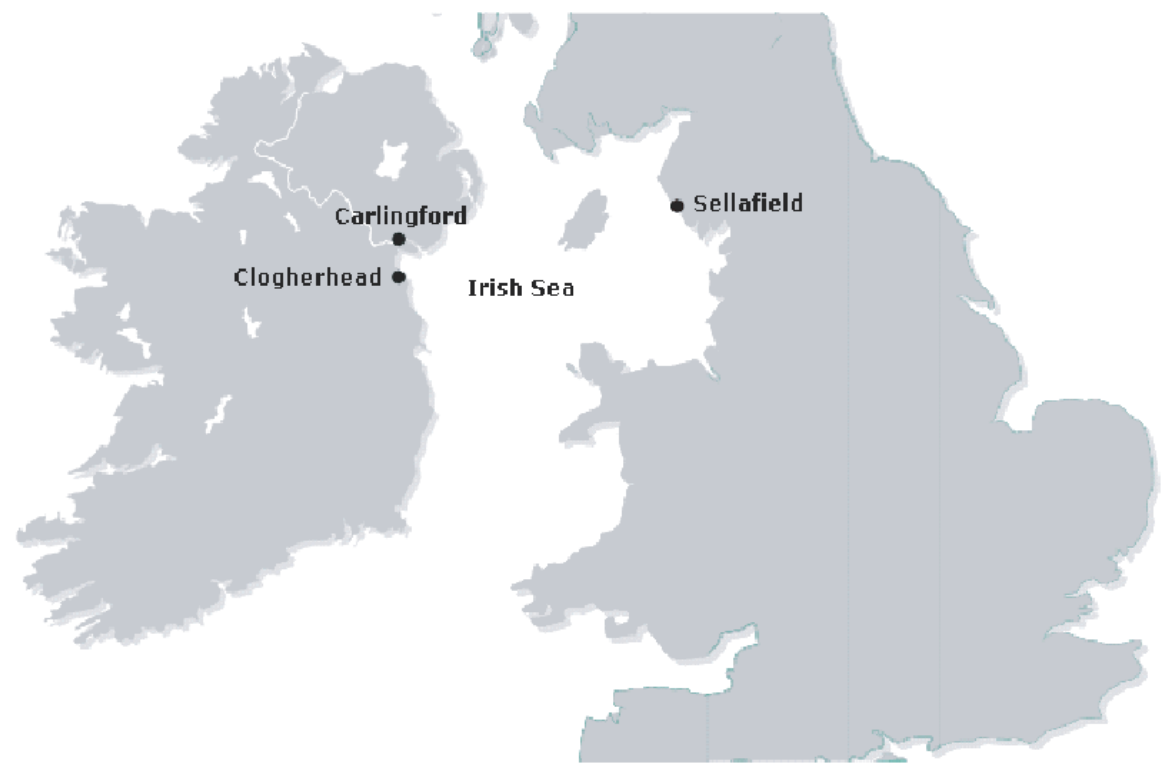

Figure 2. Sampling locations.

\section{RESULTS AND CONCLUSIONS}

\subsection{Fish}

The mean annual ${ }^{99} \mathrm{Tc}$ activity concentrations in the fish species whiting (Merlangius merlangus) landed at Clogherhead fishing port between 1990 and 2007 are presented in Fig. 3. There is considerable variation in individual ${ }^{99} \mathrm{Tc}$ activity concentrations which may be attributed to different fish catch locations since not all fish landed at Clogherhead is caught in the Irish Sea. The mean ${ }^{99} \mathrm{Tc}$ activity concentration for the pre-EARP period, 1990 to 1994, was $0.07 \pm 0.04 \mathrm{~Bq} / \mathrm{kg}$. A significant increase in activity concentrations was observed in $1996(0.64 \pm 0.05 \mathrm{~Bq} / \mathrm{kg})$ and the highest concentration in an individual sample $(2.24 \pm 0.08 \mathrm{~Bq} / \mathrm{kg})$ was measured in September 2001. Activity concentrations have decreased since 2005 in line with the reduction in discharges. The ${ }^{99} \mathrm{Tc}$ activity concentration in August 2007 was $0.25 \pm 0.02 \mathrm{~Bq} / \mathrm{kg}$ which is approximately three times higher than the pre-EARP baseline $(0.07 \pm 0.04 \mathrm{~Bq} / \mathrm{kg})$. 


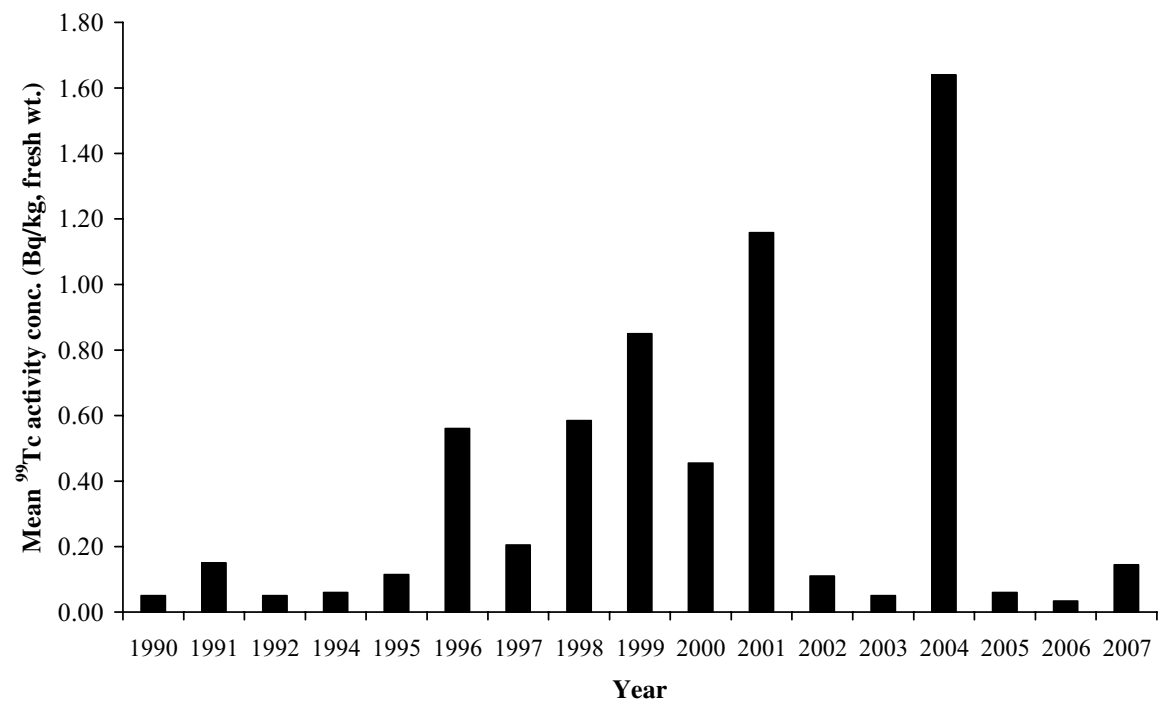

Figure 3. Mean annual ${ }^{99} \mathrm{Tc}$ activity concentrations in whiting landed at Clogherhead, 1990-2007.

\subsection{Shellfish}

The mean annual ${ }^{99} \mathrm{Tc}$ activity concentrations in prawns (Nephrops norvegicus) landed at Clogherhead fishing port and wild mussels (Mytilus edulis) sampled at Carlingford between 1990 and 2008 are presented in Fig. 4.

\subsubsection{Prawns}

The mean ${ }^{99} \mathrm{Tc}$ activity concentration in prawns for the pre-EARP period, 1990 to 1992 , was $3.48 \pm$ $1.91 \mathrm{~Bq} / \mathrm{kg}$. An increase in activity concentrations was observed in August 1994 which is consistent

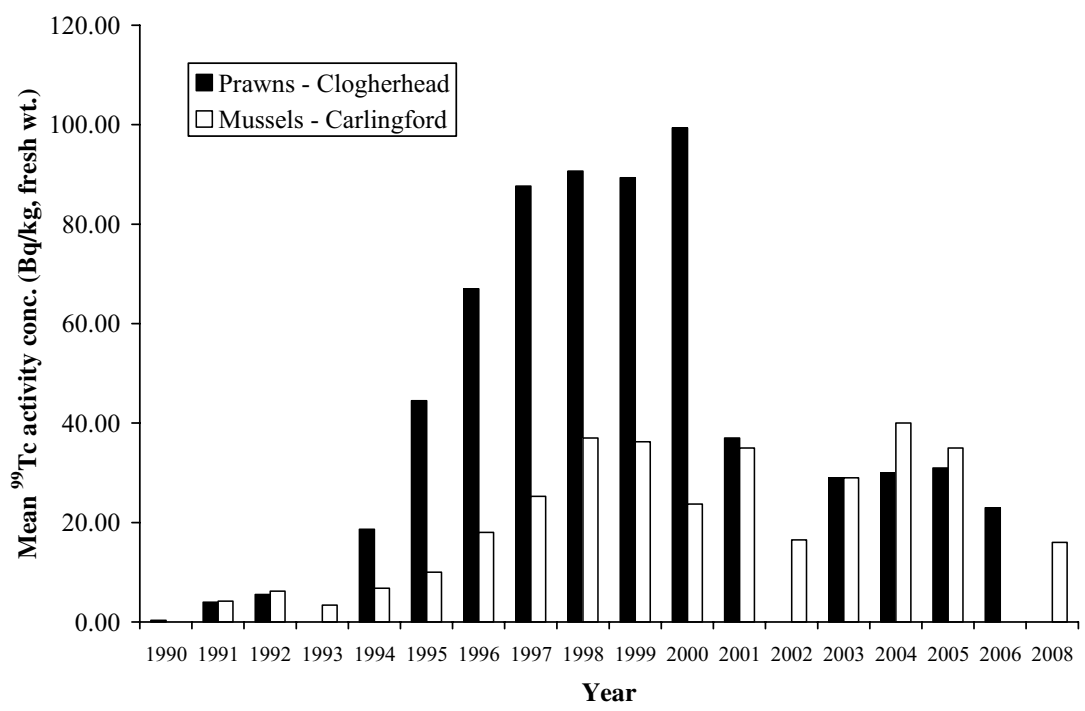

Figure 4. Mean annual ${ }^{99}$ Tc activity concentrations in prawns and mussels, 1990-2008. 
with the first increase observed in ${ }^{99} \mathrm{Tc}$ activity concentrations in the brown seaweed, Fucus vesiculosus, from the east coast of Ireland in an earlier study [2]. The highest concentration in an individual sample $(147 \pm 3 \mathrm{~Bq} / \mathrm{kg})$ was measured in August 2000. Although reduced activity concentrations have been observed since 2001, the ${ }^{99} \mathrm{Tc}$ activity concentration in 2006 was $23 \pm 1 \mathrm{~Bq} / \mathrm{kg}$ which is still approximately six times higher than the pre-EARP baseline $(3.48 \pm 1.91 \mathrm{~Bq} / \mathrm{kg})$.

\subsubsection{Mussels}

The mean ${ }^{99} \mathrm{Tc}$ activity concentration in mussels for the pre-EARP period, 1991 to 1994 , was $4.58 \pm$ $2.49 \mathrm{~Bq} / \mathrm{kg}$. An increase in activity concentrations was observed in 1995 and the highest concentration in an individual sample $(53 \pm 3 \mathrm{~Bq} / \mathrm{kg})$ was measured in May 1998. Unlike prawns, no decrease was observed in the ${ }^{99} \mathrm{Tc}$ activity concentrations until after 2005 . This may be attributed to the fact that these wild mussels, which were collected on the seashore, contained sediment which would contribute to the overall ${ }^{99} \mathrm{Tc}$ activity concentration. The ${ }^{99} \mathrm{Tc}$ activity concentration in January 2008 was $16 \pm 3 \mathrm{~Bq} / \mathrm{kg}$ which is three times higher than the pre-EARP baseline $(4.58 \pm 2.49 \mathrm{~Bq} / \mathrm{kg})$.

\subsection{Doses}

The committed effective doses from ${ }^{99} \mathrm{Tc}$ to consumers of seafood were estimated by taking the mean activity concentrations in whiting, mussels and prawns as being representative of those in fish, molluscs and crustaceans, respectively. Notional estimates of the quantities eaten daily by typical and heavy consumers of seafood were taken from RPII monitoring reports [3]. Daily consumption rates of $40 \mathrm{~g}$ of fish and $5 \mathrm{~g}$ of shellfish for a typical consumer and $200 \mathrm{~g}$ of fish and $20 \mathrm{~g}$ of shellfish for a heavy consumer were used. Shellfish consumption was assumed to be divided equally between mussels and prawns. Dose conversion factors used were those recommended by ICRP 72 [4]. Since no data was available for mussels in 2006 the value used $(20 \mathrm{~Bq} / \mathrm{kg}$ ) was taken from data published elsewhere [5] for mussels from Carlingford Lough. The committed effective doses to typical and heavy seafood consumers due to ${ }^{99} \mathrm{Tc}$ from 1991 to 2006 are presented in Fig. 5.

On average, between 1991 and 2006, 90\% of the dose due to ${ }^{99} \mathrm{Tc}$ is attributable to the consumption of shellfish, reflecting the significantly higher activity concentrations of ${ }^{99} \mathrm{Tc}$ in shellfish than in fish.

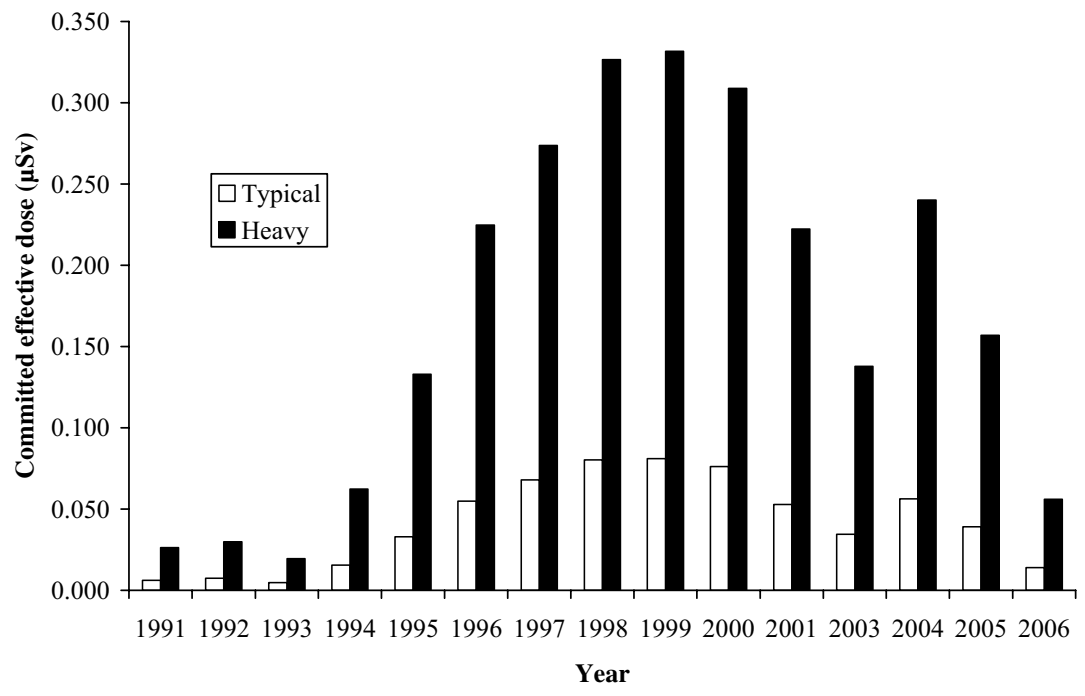

Figure 5. Committed effective dose to seafood consumers due to ${ }^{99} \mathrm{Tc}, 1991-2006$. 
The mean doses to typical and heavy consumers for the period 1991 to 1993 were 0.006 and $0.025 \mu \mathrm{Sv}$, respectively. The highest doses to both typical and heavy consumers $(0.08$ and $0.33 \mu \mathrm{Sv}$, respectively) occurred in 1999 representing a 13-fold increase on the pre-EARP baseline doses. As expected, since ${ }^{99} \mathrm{Tc}$ activity concentrations in whiting, prawns and mussels had not returned to pre-EARP levels, the doses to both typical and heavy seafood consumers in 2006 ( 0.014 and $0.056 \mu \mathrm{Sv}$, respectively) were greater than the baseline levels of the early 1990s by a factor of two. It is now known that ${ }^{99} \mathrm{Tc}$ behaves less conservatively in seawater than was previously thought [6]. Hence, although discharges of ${ }^{99} \mathrm{Tc}$ from Sellafield have returned to pre-EARP levels, contaminated sediments may become an important secondary source of ${ }^{99} \mathrm{Tc}$ in seafood in the future.

In $2006,{ }^{99} \mathrm{Tc}$ accounted for approximately $15 \%$ of the total dose to Irish seafood consumers from all artificial sources of radioactivity in the Irish Sea with ${ }^{137} \mathrm{Cs}$ continuing to be the dominant radionuclide, accounting for approximately $70 \%$ of the dose [3].

\section{References}

[1] Harvey, B.R., Ibbett, K.D., Williams, J.K. and Lovett, M.B. The determination of technetium-99 in environmental materials. Aquatic Environment Protection: Analytical Methods No. 8. (Directorate of Fisheries Research, Lowestoft, 1991).

[2] Smith, V., Fegan, M., Pollard, D., Long, S., Hayden, E. and Ryan, T.P. Technetium-99 in the Irish marine environment. J. Environ. Radioactivity 56 (2001) pp. 269-284.

[3] Smith, V., Dowdall, A., Fegan, M., Hayden, E., Kelleher, K., Long, S., McEvoy, I., Somerville, S., Wong, J. and Pollard, D. Radioactivity monitoring of the Irish environment 2006. RPII-07/03. (Dublin: Radiological Protection Institute of Ireland 2007).

[4] ICRP. Age-dependent doses to members of the public from intake of radionuclides: Part 5. Compilation of ingestion and inhalation dose coefficients. Annals of the ICRP, vol.26, ICRP publication 72. (Oxford: Pergamon Press 1996).

[5] RIFE. Radioactivity in Food and the Environment, 2006. Environment Agency, Environment and Heritage Service, Food Standards Agency, Scottish Environment Protection Agency, RIFE-12, UK (2007).

[6] McCubbin, D., Leonard, K.S., McDonald, P., Bonfield, R. and Boust, D. Distribution of technetium-99 in sub-tidal sediments of the Irish Sea. Continental Shelf Research 26, (2006) pp. $458-473$. 
